\title{
Masticatory System Biomechanical Photoelastic Simulation fot the Comparison of the Conventional and Uni-Lock Systems in Mandibular Osteosynthesis
}

\author{
José Luis Cebrián Carretero ${ }^{1}$ *, María Teresa Carrascal Morillo², Germán Vincent Fraile ${ }^{3}$ \\ ${ }^{1}$ Servicio de Cirugía Oral y Maxilofacial, Hospital Universitario La Paz, Madrid (Spain) \\ ${ }^{2}$ Departamento de Mecánica, E.T.S Ingenieros Industriales, UNED, Madrid (Spain) \\ ${ }^{3}$ Laboratorio de Prótesis Dental Vincent Dental, Madrid (Spain)
}

Received 31 August 2016 | Accepted 1 November 2016 | Published 23 December 2016

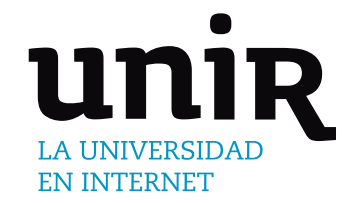

KEYWORDS

3D Photoelasticity, Biomechanical Simulator, Masticatory System Simulator, Mandibular Biomechanics, Mandibular Osteosynthesis. to study interactions between bone and osteosynthesis materials. The "Lock" systems can be considered the most favourable method due to their stress distribution in the epoxy resin mandible. 3D photoelasticity in epoxy resin models is a useful method to evaluate stress distribution for biomechanical studies. Regarding to mandibular osteosynthesis, "lock" plates offer the most favourable stress distribution due to being less
The biomechanical consequences of the interaction between titanium trauma plates and screws and the fractured mandible are still a matter of investigation. The mathematical and biomechanical models that have internal stress distributions in the bone-implant interface and mandibular structure. In the present article show a static simulator of the masticatory system to demonstrate in epoxy resin mandibular models, by mean of 3D (three-dimensional) photoelasticity, the stress distribution using different osteosynthesis methods in the aggressive to the bone.

\section{ABSTRACT}

\section{INTRODUCTION}

\begin{abstract}
A LTHOUgh cranio-maxillo-facial osteosynthesis principles were developed during the ' 60 's and 70's, their universal application was delayed until the 80 's. In this situation, the first retrospective studies with an acceptable follow-up did not appear until 1990. In these papers osteosynthesis showed its superiority over any other traditional method for fracture treatment $[1,2,3]$.

In the field of mandibular osteosynthesis, research continues to focus on the size, shape, number, and biomechanics of plate/screw systems to improve surgical outcome.

In conventional bone plating stability is achieved systems when the head of the screw compresses the fixation plate to the bone as the screw is tightened (Fig. 1). Morbidity with these systems is commonly related to: 1) mobility and hardware failure; 2) alterations in the alignment of the segments that cause changes in the occlusal relationship; 3 ) resorption of the bone cortex adjacent to the plate. In some cases, if the plate is not contoured precisely and is not in intimate contact with the bone or if the host is compromised (medically or nutritionally), the "race" between fracture healing and cortex resorption will be lost and will result in unstable fixation [4].
\end{abstract}

\footnotetext{
* Corresponding author.

E-mail address: josel.cebrian@salud.madrid.org
}

The Locking plate/screw systems have certain advantages over conventional plates and screws. They achieve stability through a device that "locks" the screw to the plate while the screw shaft secures the bone. Theoretically, they offer the advantages of: 1) less screw loosening; 2) greater stability across the fracture site; 3) less precision required in plate adaptation because of the "internal/external fixator"; and 4), less alteration in osseous or occlusal relationships when the screw is tightened $[5,6]$.

The lock between the plate and screw obviates the requirement for compression between the plate and mandible as is required in a conventional screw plate system (3) and fewer screws might be needed to achieve maximal load resistance $[7,8]$.

Although some biomechanical studies have focused on the higher stability of these "locking" systems in comparison to non-locking systems (Gutwald, Haug), the theoretical advantage of avoiding bone compression and cortical plate resorption has not yet been biomechanically proven.

There are two requirements to prove this:

1. First, it is necessary to create a simulator of the studied biomechanical system that accounts for the variability of the in vivo interaction between human and non-human tissues. [9-11]

2. It is also necessary to develop a technique that allows us to analyze the interphase between the implant and bone. $[11,12]$ 
Numerous in vitro models of fracture fixation have been described in the literature. These include cadaveric mandible models: freshly harvested ovine/sheep mandibles; porcine/sheep mandibles and bovine/cow ribs. Although different simulators have been developed, they have never actually been employed to explore the biomechanical interaction between implant and bone [12].

The purpose of the present investigation is to develop a biomechanical simulator of the masticatory system so as to evaluate and compare the mechanical behavior of locking and conventional plate and screw systems placed under ideal conditions employing the photoelastic techniques.

\section{Methods}

\section{A. Photoelasticity and Tension Freezing Method}

Photoelasticity is based on an optic phenomenon called occasional birrefringency. It takes place when a transparent material, with specific characteristics, is put under mechanical stress and then observed in a polarized light field; under this light, a constant isochromatic band, that are directly related with the tensional force in each area. Polarized light reveals a constant pattern of isochromatic bands in the transparent material that are directly related with the stress level in each area.

The stress freezing procedure takes advantage of resin epoxy photoelasticity. This type of resin has two molecular phases, and when baked/heated for 2 hours at $70^{\circ} \mathrm{C}$ one of the phases becomes viscous, while the other, which is crystalline remains solid. The model is heated and exposed to a stress load, the solid phase of the material is deformed, with the resulting internal stress loads being revealed by the isochromatic lines revealed by polarized light. The difference in tension/stress between the two bands is given by the following formula:

\section{Stress $/$ Tension Differential $=\mathrm{Nx}$ F $/ \mathrm{h}$}

Where, $\mathrm{N}$ is an a-dimensional constant for each band whose value rises with the stress in the area.

" $F$ " is constant that is related with the kind of material and " $h$ " is thickness (Fig 1).

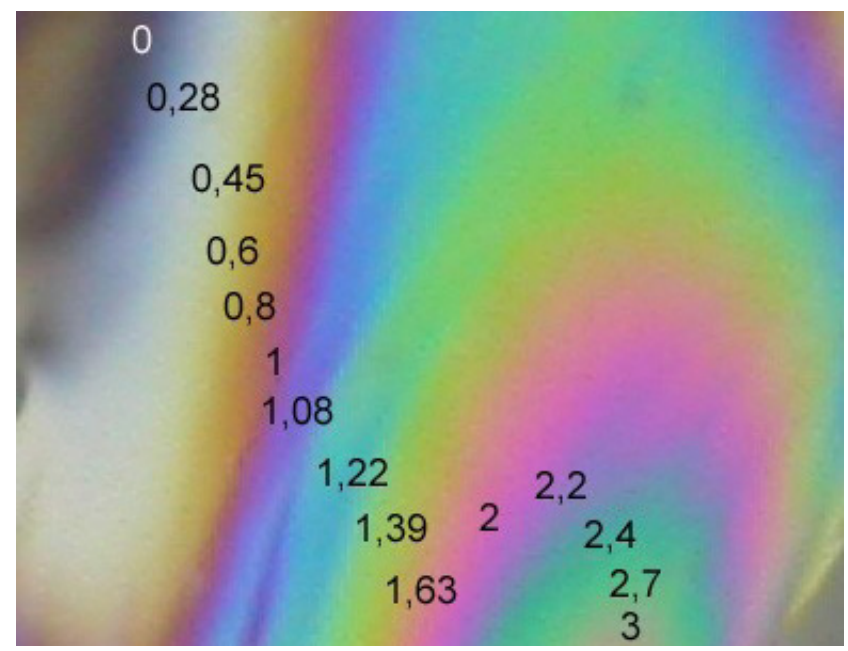

Fig. 1. Isocromatics spectrum where each number represent " $n$ " value in different frames.

\section{Biomechanical SimUlator}

1:1 scale dentate mandibles made of epoxy resin, which is an acceptable substitute for bone in studies of mandibular fixation, were used to simulate the intact mandible. The mandibular model was mounted on a polyurethane cranium. The mastication musculature (Fig. 2) was mounted placing screws in the points at which muscles are inserted to hold elastic bands that create forces like those applied by the masticary muscles. The following muscles were simulated: maseteri, lateral and medial pterigoid, temporal and depressor muscles. So as to reproduce the mechanics of the system, stresses proportional to those calculated by Meyer [13] for healthy individuals in maximum intercuspidation were applied.

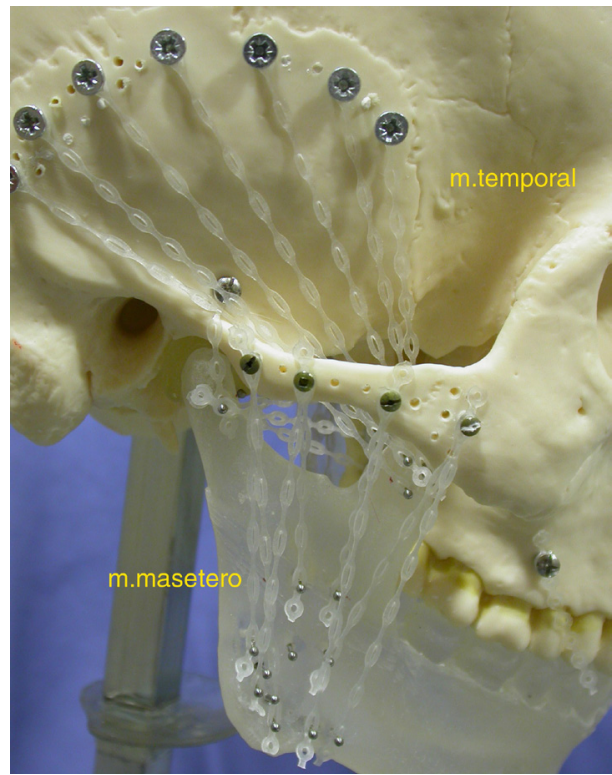

Fig. 2. Mastication musculature.

\section{AsSAYS}

Angle fractures were caused/provoked in the right mandibular angle of two mandibles. They were fixed using two different osteosynthesis methods:

1. Conventional miniplates: 2.0 miniplates.

\section{2. "Locking" plates: 2.4 locking plates. (Fig. 3)}

To study the interface between bone and screw osteosoynthesis material was removed after applying the freezing tension method and the mandible was cut into $5 \mathrm{~mm}$ slices from angle to angle.

These mandibular slices were polished until they were smooth/ transparent and before being observed under the polaroscope.

Applying the stress differential formula and considering " $\mathrm{f}$ " and " $\mathrm{h}$ " as constants, we can see that semiquantitatively, the greater the $\mathrm{N}$, the higher the stress.

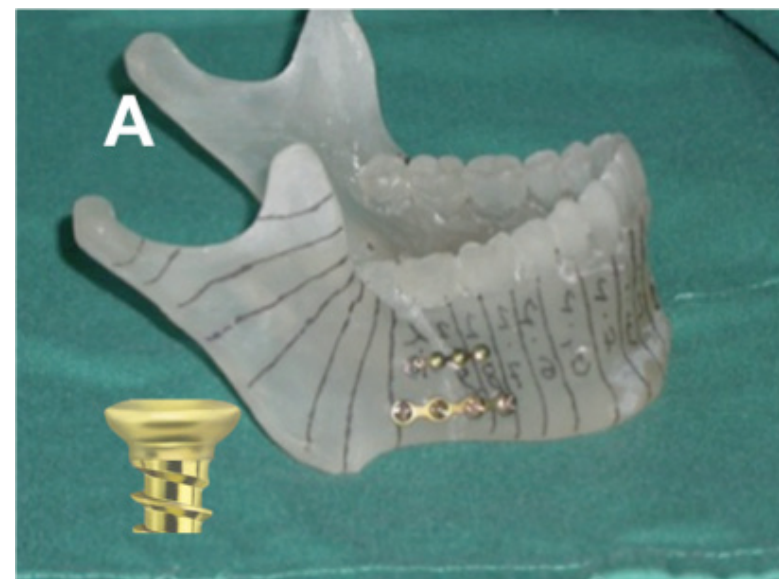




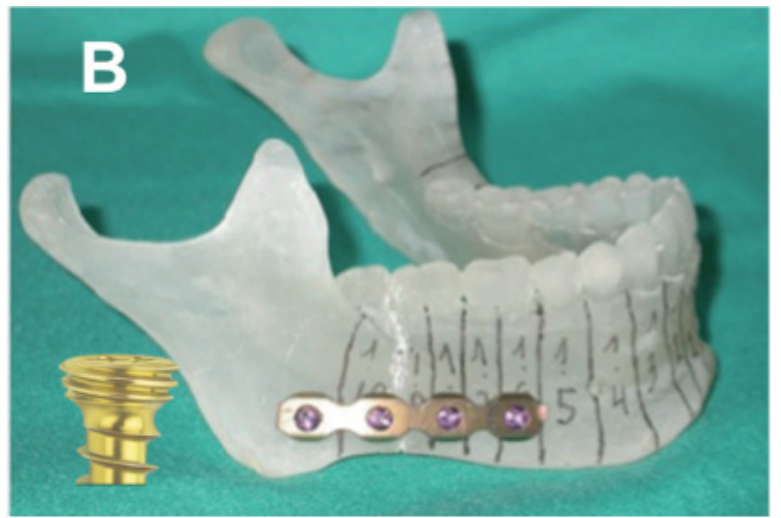

Fig. 3. Epoxi resin mandibular prototype. A. Ostheosinthesis with 2.0 miniplates. B. Ostheosynthesis with "lock" type plate.

\section{Results}

When the screw tightened the plate directly onto the mandible, the stresses related with the compression forces were concentrated in the external cortical bone, in the area in which the plate was apposed to the plate. These stress lines were very intense along the length of the screw, reaching the basilar area and alveolar bone, with an important reaction in the opposite cortical bone (Fig 4. A and B).
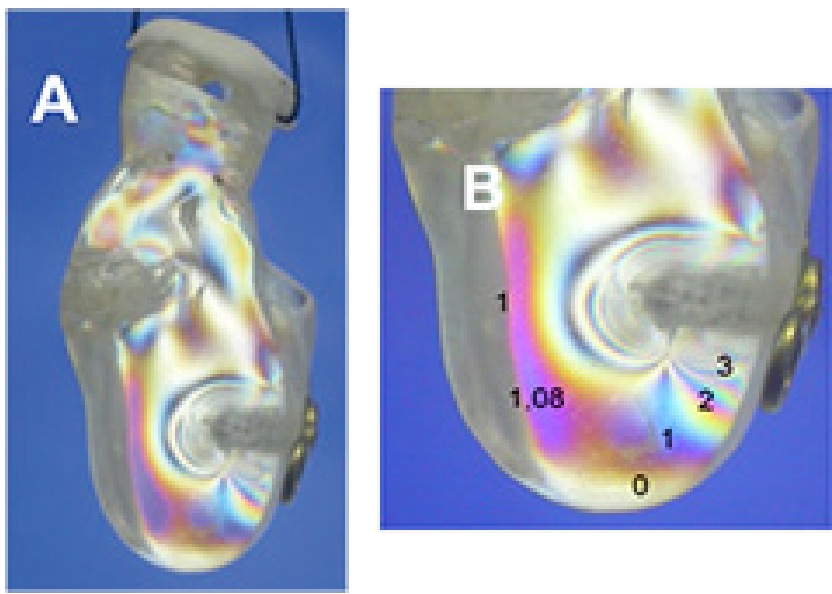

Fig. 4. A. Ostheosynthesis with 2.0 conventional plates. B. Notice the high tension concentration related with compresive strenghts surrounding the screw and both bony corticals.

On the contrary, when a locking plate/screw system was used, the compression force lines on the mandible/in the mandible were much less. Fig. 5.A and B show how the concentration of stresses was less than with the conventional plate system, and, in addition, stress lines were limited to the tip of the screw without extending to the proximal part of the screw. In the same way, there was no compression over the cortical bone in contact with the plate, or even less stress reaction in the contralateral cortex.

Observation of the stress lines along the cortical slices shows that both the maximum intensity and the maximum density were less than with the previous model.

In cases in which 2 conventional $2.0 \mathrm{~mm}$ miniplates (Fig 6) were used, the concentration of stress lines along the length of the implant, independently of implant length, and along the external cortical bone, was high. The isochromatic bands surrounding the two screws expanded into each other, creating an area of concentrated high stresses between the two screws.
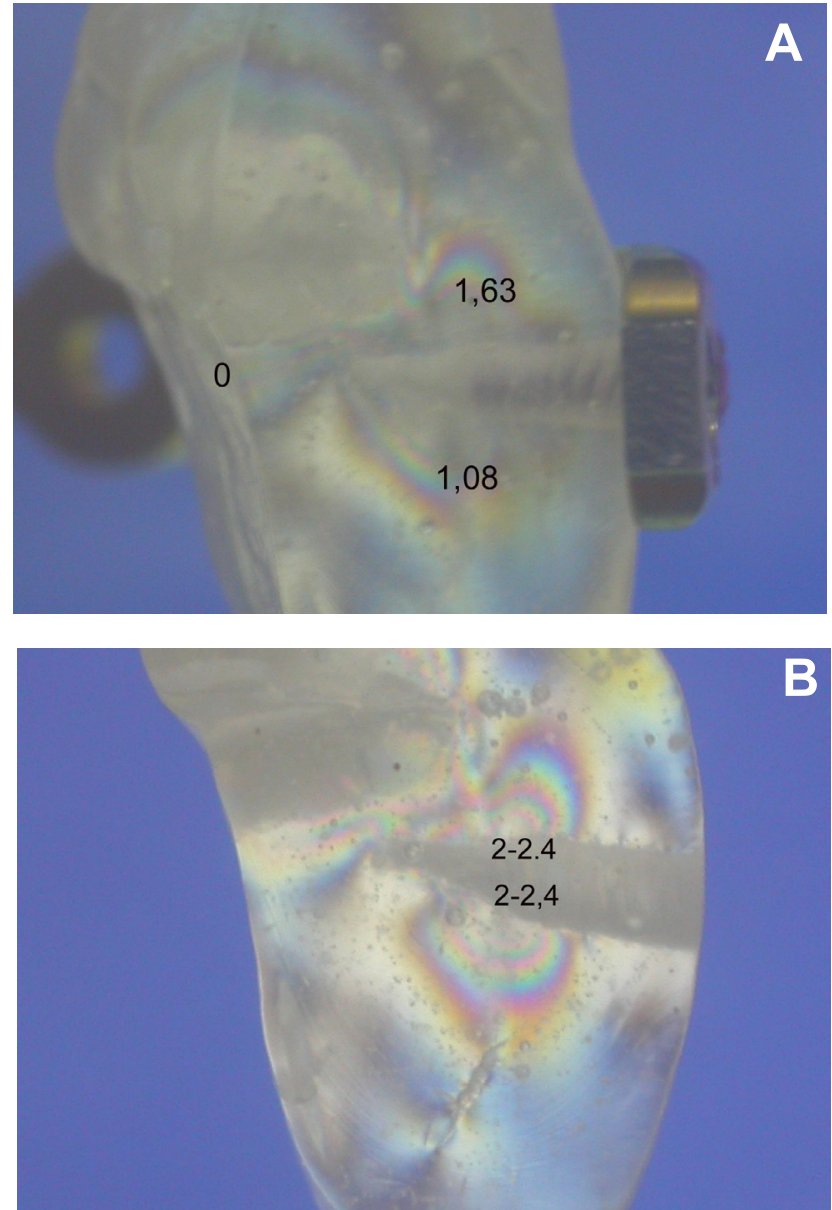

Fig. 5. A and B.-«Lock» system. Notice the low tensión along the screw, with only higher tensions in the tip area.

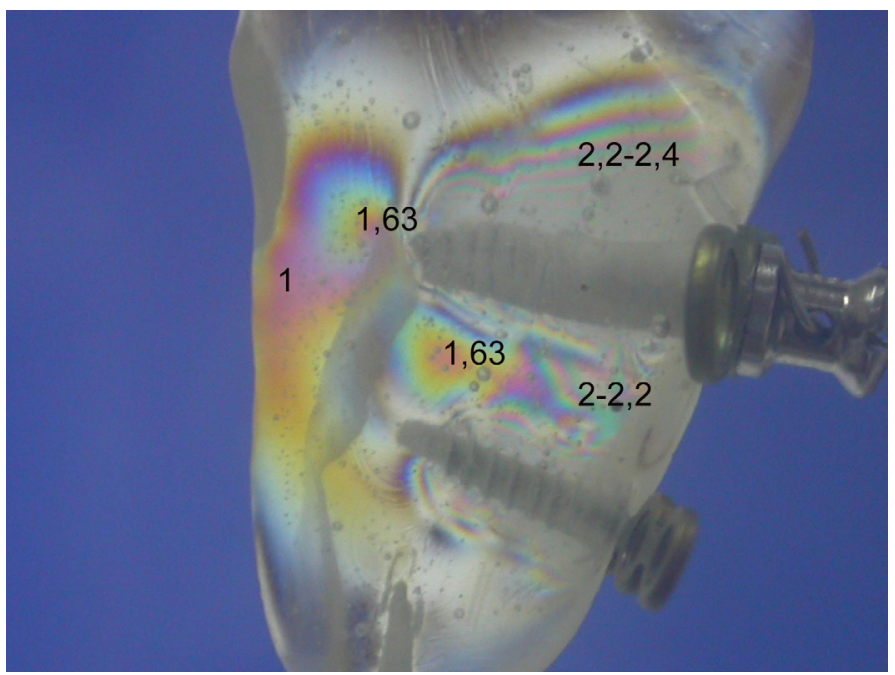

Fig. 6. Tension spectrum surrounding two 2.0 conventional screws. Notice the high tension's concentration along the hole screw body, over both cortical areas and in the cancellous bone between both screws.

\section{DisCUSSION}

During the past thirty years, research into osteosynthesis has focused on the achievement of the most biocompatible material in terms of composition, shape and size. Nevertheless, only a few biomechanical studies have analyzed what is the ideal osteosynthesis. It makes sense that this osteosynthesis should function without interrupting, at all, or 
as little as possible, the normal tension-sress pattern in the mandible $[14,15]$.

Conventional bone plate/screw systems require precise adaptation of the plate to the underlying bone and screw compression to maintain the occlusal relationship and fracture stabilization. This system ensures primary healing, but a long-term side effect could be screw loosening and external cortical bon resorption resulting from plate compression $[7,8]$.

The most significant advantage of locking systems may be that they make it unnecessary for the plate to have intimate contact with the underlying bone in all areas. As the screws are tightened, they "lock" to the plate, thus stabilizing the segments without the need to compress the bone to the plate. This obviates the risk that screw insertion will alter the reduction. This theoretical advantage is certainly more important when using large bone plates like reconstruction plates, which can be very difficult to adapt perfectly. The other problem is pressure from the screw. The amount of stability provided across the fracture osteotomy gap is greater than when standard non-locking screws are used.

In an attempt to explore the relationship between bone, plates and screws, the present study employed photoelasticity and freezing tension method to analyze the interphase between bone and plates and screws.

Photoelasticity has been widely employed to evaluate osteosynthesis methods. Perhaps the most influential studies are those of Champy et al, which, between 1970-1980, subjected photoelastic resin blocks to stress in order to draft the basic fundamentals of osteosynthesis $[12,13$, 14]. At this point, several studies employing photoelasticity to evaluate osteosynthesis options for traumatology, orthodontics ad mandibular reconstruction after a hemimandibulectomy have been done $[16,17$, 18].

All these studies employed systems that subjected a mandibular model to a bidimensional study of the surface.

The advantages of tension freezing methods in mandibular slices are double:

1. They allow the study of the interphase between bone and screws.

2. They allow tridimensional studies if the mandibular slices are analyzed sequentially.

The novelty of the present experimental design is that it applies a stress-freezing technique to interpret the stress forces created by the insertion of the osteosynthesis materials, since, even though the component or implant is removed, the stress lines are "memorized".

The experiments in our study have shown how the compression of the plate by the screw in the non-locking systems is directly transmited to the bone into the cortical bone. In this situation, experimental studies have shown a disruption of cortical blood supply directly beneath the bone plate, favoring bone resorption $[19,20]$.

This is very important in the body of the mandible and in compromised patients in which vascularization is impaired.

This over pressure is avoided when locking systems are used

Although reports of the use of locking plate and screw systems for maxillofacial reconstruction have existed for more than three decades, their clinical use has not become popular until the last decade [21] Herford and Ellis concluded that "the use of a locking plate/ screw system was found to be simple and it offers advantages over conventional bone plates by not requiring the plate to be compressed to the bone to provide stability $[6,22]$.

The first biomechanical comparison of locking and non-locking plates to appear in the maxillofacial surgical literature was made by Gutwald in 1999 [5]. That investigation was performed using 16 cadaver mandibles. They concluded that a higher stability was achieved with locking plates. If we add this advantage to the fact of the decreased potential bone damage we have demonstrated here, we can conclude that the use of locking plates and screws is clinically advisable.

Recent studies involving the use of miniplates have questioned the role of biomechanical testing because of conflicting data when in vivo and in vitro models are compared. Biomechanics is only one factor to be considered in the treatment of mandibular fractures and many others may also be involved.

The main disadvantage of the locking system is cost.

Therefore functional overloading of regions that need not undergo compressive forces is much greater in the conventional systems. Although it is yet to be proven "in vivo", it can be supposed that this system will avoid compromising external cortical bone during healing.

We used the $2.4 \mathrm{~mm}$ locking system in this study because at the time of the experimental work the single $2.0 \mathrm{~mm}$ lock plate was still controversial for treating body angle fractures $[21,22]$, but since then, similar fixation rates have been reported with the $2 . \mathrm{mm}$ plate, which offers a similar, or even better stability than conventional osteosynthesis systems $[23,24]$.

It is true thah biomechanicals aspects are only one side of the problema when we are facing mandibular fractures, but it is also clear that the bone and tissue care that is ensure by "lock" systems has been clinically proven. In fact, this systems are heavily recommended for savage in those case in which ostheosynthesis has failed [25, 26, 27].

\section{CONCLUSION}

In the present study we propose a reliable and predictable model to explore biomechanichal characteristics of muscle-skeletal masticatory system.. The system is particularlly useful to study ostheosynthesis in case of mandibular fractures offering a semi-cuantitative assesment about stress and tensions that are working in the fractured system. In this sense it has allowed us to conclude how "locked" systems are the less harmful for the bone and also those who are more respectful with mandibular forces and tensions. This study shows hoe photoelasticity and freezing tensions methods are very useful systems to study mandibular biomechanics as it has been shown in preliminary reports $[25,26]$.

\section{ACKNOWLEDGEMENTS}

We appreciate the cooperation of Dr. Rodríguez Avial director of the Laboratory of Materials of the ETSII of the UNED where this study was developed. The authors declare no interest conflict.

\section{REFERENCES}

[1] Thaller SR, Reavie D, Daniller A. Rigid internal fixation with miniplates and screws: a cost-effective technique for treating mandible fractures? Ann Plast Surg. 1990;24:469-74.

[2] Hoffman WY, Barton RM, Price M, Mathes SJ. Rigid internal fixation vs. Traditional techniques for the treatment of mandible fractures. J Trauma. 1990;30:1032-5.

[3] Moreno JC, Fernández A, Ortiz JA, Montalvo JJ. Complication rates associated with different treatment for mandibular fractures. J Oral Maxillofac Surg. 2000;58:273-80.

[4] Klotch DW, Gal TJ, Gal RL. Assessment of plate usemandibular reconstruction: Has changing technology made a difference? Otolaryngol Head Neck Surg. 1999;121:388-92.5.

[5] Gutwald R. Biomechanical stability of an internal mini fixation system in maxillofacial osteosynthesis. J Med Biol Eng Comp. 1999;37:S280.

[6] Hertford AS, Ellis E. Use of a locking reconstruction bone plate/screw system for mandibular surgery. J Oral Maxillofac Surg. 1998;56:1261-5.

[7] Haug RH, Street CC, Goltz M. Does plate adaptation affect stability? A biomechanical comparison of locking and nonlocking plates. J Oral 
Maxillofac Surg. 2002;60:1319-26.

[8] Haug RH, Fattahi TT, Goltz M. A biomechanical evaluation of mandibular angle fracture plating techniques. J Oral Maxillofac Surg. 2001;59:1199-210.

[9] Bredbenner TL, Haug RH. Substitutes for human cadaveric bone in maxillofacial rigid fixation research. Oral Surg Oral Med Oral Pathol Oral Radiol Endod. 2000;90:574-80.

[10] Pacey MN, Haake SJ, Paterson EA. A novel instrument for automated principal stress separation in reflection photoelasticity. J Test Eval. 2000;28:229-35.

[11] Champy M, Lodde JP, Jaeger J, Wilk A. Ostéosynthéses. Mandibulaires selon la technique de Michelet. Bases biomécaniques. Rev Stomatol Chir Maxillofac. 1976;77:569-76.

[12] Gross MD, Nissan J, Samuel R. Stress distribution around maxillary implants in anatomic photoelastic models of varying geometry. Part I. J Prosth Dentistry. 2001;85:442-9.

[13] Meyer U, Vollmer D, Benthaus S, Felczegi E, Joos U, Piffko F. Experimentelle un finite element analysie der biomechanik des unterfiekersunter belastung. Mund KieferGesichtschir. 2000; 4: 14- 20.

[14] Kim YK, Nam KW. Treatment of mandible fractures using low profile titanium miniplates: preliminary study. Plast Reconstruc Surg. 2001;108:38-43.

[15] Rudman RA, Roshental SC, Shen C, Ruskin JD, Ifju PG. Photoelastic analysis of miniplate osteosynthesis for mandibular angle fracture. Oral Surg Oral Med Oral Pathol Oral Radiol Endod. 1997;84:129-36

[16] Shetty V, Caputo AA. Biomechanical validation of the solitary lag screw technique for reducing mandibular angle fractures. J Oral Maxillofac Surg. 1992;50:603-7.

[17] YiZ, Jian-Guo Z, Guang-Yan Y. Reconstruction plates to bridge mandibular defects: a clinical and experimental investigation in biomechanical aspects. Int J Oral Maxillofac Surg. 1999;28:445-50.

[18] Champy M, Lodde JP. Synthéses mandibulaires. Localisation de synthése en fonction des contraintes mandibulaires. Rev Stomatol Chir Maxillofac. 1976;77:971-6.

[19] Weinans H, Huiskes R, Grootenboer HJ. Quantitative analysis of bone reactions to relative motions at implant-be interfases. J Biomechanics. 1993;26:369-82.

[20] Rietbergen B, Huiskes R, Weinam H, Sumner DR, Turner TM, Galante JO. The mechanics of bone remodeling and resorption around prefitted systems. J Biomechaics. 1993;26: 369-82.

[21] Alpert B, Gutwald R, Schmelzeisen R. New innovations in craniomaxillofacial fixation: the 2.0 lock system. Keio J Med. 2003;52:120-7.American Cancer Society. Breast Cancer

[22] Ellis E, Graham J. Use of a $2.0 \mathrm{~mm}$ locking reconstruction bone plate/ screw system for mandibular fracture surgery. J Oral Maxillofac Surg. 2002;60:642.

[23] Cebrián JL. Desarrollo de un simulador estático para estudios biomecánicos foto-elásticos del sistema músculo-esquelético masticatorio. Tesis.

[24] Gbara A, Heiland M, Schmelzle R, Blake F. Mechanical aspects of a multidirectional, angular stable osteosynthesis system and comparison with four conventional systems. J Craniomaxillofac Surg. 2008;36:152-6.

[25] Navarro I, Cebrián JL, Demaría G, Chamorro M, López-Arcas JM, Mún oz JM, et al. Fracaso de la osteosíntesis mandibular. Consideraciones biomecánicas y tratamiento. A propósito de dos casos clínicos. Rev Esp Cir Oral y Maxilofac. 2009;31:122-7.

[26] Cebrián JL, Carrascal MT, Vincent G, Ortiz de Artinano F. Estudio biomecánico experimental del sistema musculo-esquelético masticatorio Aplicaciones para el estudio de la osteosíntesis. Rev Esp Cirug Oral y Maxilofac.2009;31:39-45 at.

[27] Cebrián-Carretero JL, Sánchez Burgos R, Carrascal-Morillo MT, VincentFraile G, Ortiz de Artiñano F, Burgueño García MAComparación biomecánica entre los sistemas convencionales y uni-lock en osteosíntesis del ángulo mandibular. Estudio fotoelástico. Rev Esp Cir Oral y Maxilofac. 2012;34:1-7.

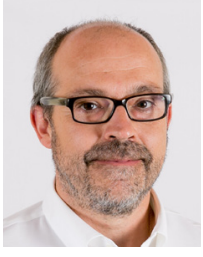

\section{José Luis Cebrián Carretero}

José Luis Cebrián Carretero got his Medical Degree Universidad Autónoma de Madrid (UAM) in 1993. He is $\mathrm{PhD}$ by the same university in 2005 . He also studied Oral and Maxillofacial training H.U. La Paz from 1995 to 2000. He got is Dental Degree in the Universidad Europea de Madrid (UEM ) in 2009. He is fellow of the European Board of Oral and Maxillofacial Surgery, Specialist in Oral and Maxillofacial Surgery, La Paz University Hospital, Madrid and Chief of Division in Oral and Maxillofacial Surgery, La Paz University Hospital, Madrid, and Director of Oral and Maxillofacial Surgery Departments at Quironsalud Hospital Sur de Madrid y Clínica La Luz. Finally he is Vice-President of the SECOM (Spanish Society of Oral and Maxillofacial Surgery). He is author of 2 books, 15 chapters and more than 50 scientific articles. His main research areas are Implantology, Head and Neck Oncologic Surgery and Orthognatic and Oral Surgery.

María Teresa Carrascal Morillo

Associate Professor within the Department of Mechanics at the Higher Technical School of Industrial Engineering of the National University of Distance Education (UNED). Director of Biomechanics Laboratory tests in which biological and synthetic materials are made.

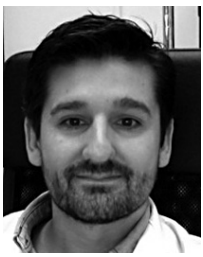

\section{German Vincent}

German Vincent is dental prosthesis technician, specialist surgical splints for orthognathic surgery. He works in his own laboratory called Vincentdental in Madrid. He is a national speaker at numerous courses of orthodontics and facial deformities related pathology and Temperomandibular joint. 